\title{
Stepped-wedge cluster randomised trials: where, when and why?
}

\author{
Michael Grayling*, James Wason, Adrian Mander \\ From 3rd International Clinical Trials Methodology Conference \\ Glasgow, UK. 16-17 November 2015
}

The stepped wedge (SW) cluster randomised trial (CRT) design is being utilised at increasing pace. However, little is known about the standard of reporting of such trials, or how useful the design has proven to be in hindsight. Moreover, much debate exists around when the design should be preferred to the more classical parallel group (PG) CRT. Here, we address these issues by first conducting a thorough review of all SW-CRTs. We are able to ascertain not only the quality of reporting, but also the stated reasons for the design's use. We are also able to highlight instances where, on reflection, alternative designs may have been preferable. We then present a critical appraisal of the design from a logistical and ethical standpoint. With our findings we propose methodology for the incorporation of early stopping for futility within a SW-CRT. Finally, we compare this new design in terms of expected efficiency to the conventional approach as well as to several variants of the PGCRT design. We assess which is optimal in a range of settings, including balancing the required sample size with the required time for trial completion. We find that to date the standard of reporting of SW-CRTs has been mixed in quality. However, there are many instances in which the design is preferable to the PGCRT approach. In particular, through the addition of early futility stopping, sample size savings under the null hypothesis of more than $30 \%$ can be observed, at little cost to the length of the trial.

Published: 16 November 2015

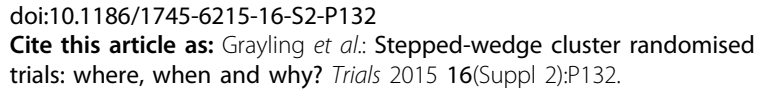

MRC Biostatistics Unit, Cambridge, UK
Submit your next manuscript to BioMed Central and take full advantage of:

- Convenient online submission

- Thorough peer review

- No space constraints or color figure charges

- Immediate publication on acceptance

- Inclusion in PubMed, CAS, Scopus and Google Scholar

- Research which is freely available for redistribution 